\title{
OPEN
}

Published online: 10 March 2020

\section{Author Correction: Synthesis and characterization of polyethylene glycol-phenol-formaldehyde based polyurethane composite}

Juan Liu $\mathbb{1}$, RiQing Chen, ChunPeng Wang, YongJun Zhao \& FuXiang Chu

Correction to: Scientific Reports https://doi.org/10.1038/s41598-019-56147-x, published online 20 December 2019

The original version of this Article omitted an additional affiliation for RiQing Chen, ChunPeng Wang and FuXiang Chu. The correct affiliations for these authors are given below:

RiQing Chen:

Institute of Chemical Industry of Forestry Products, CAF, Nanjing, 210042, China

Institute of Forest New Technology, CAF, Beijing 100091, China

ChunPeng Wang:

Institute of Chemical Industry of Forestry Products, CAF, Nanjing, 210042, China

Institute of Forest New Technology, CAF, Beijing 100091, China

FuXiang Chu:

Institute of Forest New Technology, CAF, Beijing 100091, China

Chinese Academy of Forestry, Beijing, 100091, China

This error has now been corrected in the PDF and HTML versions of the Article.

(c) (i) Open Access This article is licensed under a Creative Commons Attribution 4.0 International License, which permits use, sharing, adaptation, distribution and reproduction in any medium or format, as long as you give appropriate credit to the original author(s) and the source, provide a link to the Creative Commons license, and indicate if changes were made. The images or other third party material in this article are included in the article's Creative Commons license, unless indicated otherwise in a credit line to the material. If material is not included in the article's Creative Commons license and your intended use is not permitted by statutory regulation or exceeds the permitted use, you will need to obtain permission directly from the copyright holder. To view a copy of this license, visit http://creativecommons.org/licenses/by/4.0/.

(c) The Author(s) 2020 